\title{
Fatty Acid Composition and Biological activity of Zizyphus spina-christi L Seeds Oil from Sudan
}

\author{
Fath El-Rahman A., Munged I., Tegani A., Ibrahim A., Mohamed A., Mohamed H., Mubarak A.
}

\begin{abstract}
Zizyphus spina-christi $L$ is an important medicinal plant belonging to family Rhamnaceae is used to treatment various diseases such as bronchitis, anemia, diarrhea, diabetes, skin infections ,digestive disorders, weakness, liver complaints, obesity, of appetite, fever, pharyngitis, urinary troubles, loss .The main objective of this study was to identify the fatty acid composition and evaluate the antimicrobial activity of Sudanese Zizyphus spina-christi $L$ seeds oil, the plant fruits were purchased from Omdurman market, separated seeds and crushed to a fine powder then extracted with n- Hexane using a soxhlet, the oil obtained was analysis by GC/MS technique to give unsaturated fatty acids $(61.60 \%)$ and saturated fatty acids $(38.40 \%)$, also oil was tested for the antimicrobial activity.
\end{abstract}

Index Terms-Seeds Oil, Zizyphus spina-christi L, Fattey Acid

\section{INTRODUCTION}

The plant Zizyphus spina-christi L is belongs to the family Rhamnaceae Commonly known in English Christ's thorn and in Arabic Nabak or Nabag, Nabaj, (fruit), Sidir (tree) [1], Usually in Arabic the fruits have the name of the tree [2], it is an evergreen trees and shrubs distributed in the tropical and subtropical regions of the world. And grows profusely in Sahara and Sahel, from Senegal to the Sudan and Arabia [3]. It is Shrubs or small trees, $10-15 \mathrm{~m}$ tall, Stem park of the tree is light grey, very cracked, and scaly [4],Leaves are less than 3 $\mathrm{cm}$. long ovate-lanceolate or ovate-elliptic, with acute or obtuse apex (1-3.5) cm. broad [1,5]. Flowers are small $(10-25)$ in heads beside leaves, yellow green stalk and calyx hairy white [5], Fruits sub globose to globose drupes, yellow, reddish or red-brown, usually $2 \times 1 \mathrm{~cm}$., fruit pulp astringent to taste [1],the taste like a mixture of apples and date s which can be eaten as fresh as well as I dried form [6]. Many parts of Zizyphus spina-christi $\mathrm{L}$ has been used for different purposes in folklore medicine. The roots are used to cure and prevent skin diseases [7] treatment against headaches, while spines and ashes are applied to heal snake bites, macerated roots are used as an ant purgative [2]. Bark is used to clean wounds and sores, while the gum that exudes from the tree in hot weather

Fath El-Rahman A., Department of Chemistry \& Biology, Faculty of Education, Omdurman Islamic University, Khartoum, Sudan

Munged I., Department of Chemistry, Faculty of Applied \& Industrial Sciences., Bahri University, Khartoum, Sudan.

Tegani A., Department of Chemistry \& Biology, Faculty of Education, Omdurman Islamic University, Khartoum, Sudan

Ibrahim A., Department of Chemistry \& Biology, Faculty of Education, Omdurman Islamic University, Khartoum, Sudan

Mohamed A., Department of Chemistry \& Biology, Faculty of Education, Omdurman Islamic University, Khartoum, Sudan

Mohamed H., Department of Chemistry \& Biology, Faculty of Education, Omdurman Islamic University, Khartoum, Sudan

Mubarak A., Department of Chemistry \& Biology, Faculty of Education, Omdurman Islamic University, Khartoum, Sudan is used in eye remedies, Ash of wood mixed with vinegar is applied to heal snake bites, and the decoctions of the bark are used to treat intestinal spasms. [2] The powder of the twigs is used externally to treat rheumatism and scorpion sting [8].
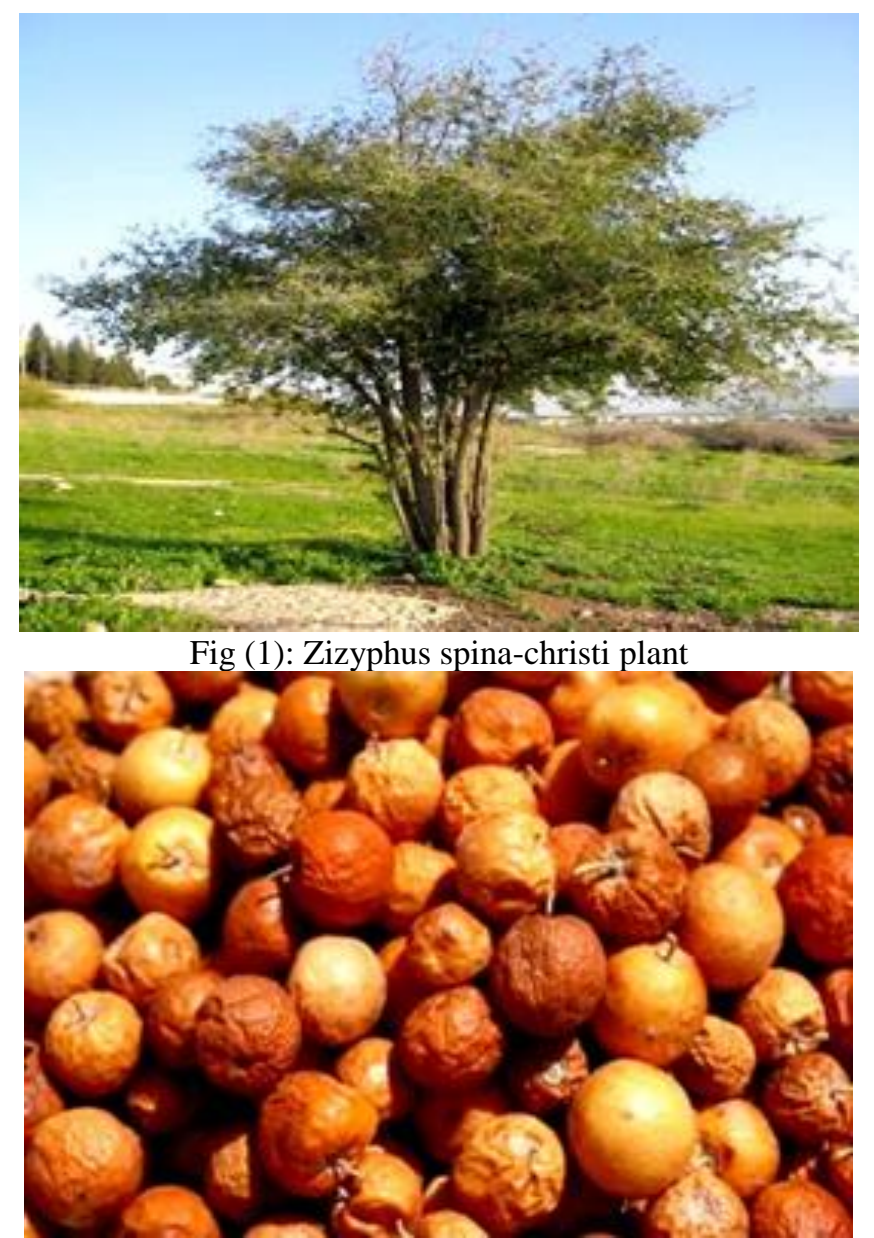

Fig (2): Zizyphus spina-christi fruits

Zizyphus spina-christi L leaves are traditionally used to treatment some diseases such as ulcers, wounds, eye diseases, bronchitis, and skin diseases as an anti-inflammatory agent, malaria [7, 9]. Also applied as poultices and are helpful in liver troubles, asthma and fever [10]. Leaves and young branches are used as an anti-inflammatory for eye wash, treat toothache and stomachache and as an anti-rheumatic [10] Powdered leaves is used to heal swellings and Boiled leaves are applied to various surface wounds and against diarrhea. Leaves are boiled in water and used as a shampoo or mixed with lemon and applied to the face and hair to soften or to soothe it. [2] The honey collected from the flowers is an excellent flavor [3]. The fruits of Z.spina-christi are very nutritious fruits that are usually eaten as fresh. The fruits are applied on cuts and ulcers, Pneumonia, dysentery, scorpion stings, cough, constipation, intestinal worms, and fever [12] 
and to treat pulmonary ailments [10] bronchitis, and tuberculosis. it is also used to relief digestive disorders, obesity, urinary troubles and microbial infections [7]. And are eaten to treat diarrhea and malaria and as an antispasmodic [2]. Fruits and crashed kernels are eaten to treat chest pains, respiratory problems and as a tonic [2].The seeds are sedative and are used to halt nausea, vomiting and abdominal pain associated with pregnancy [13]. The leaves and seeds of these plant are contain alkaloids ,flavonoids, saponins, sterols, tannins, lipids, triterpenes, protein, carbohydrates, cyclopeptide mucilage, calcium and magnesium $[2,3,6,14]$.

\section{MATERIALS AND METHODS}

\subsection{Sample collection:}

The fruits sample of Zizyphus spina-christi $L$ was purchased from Omdurman Market Khartoum, Sudan on January 2018. The fruits material was identified and authenticated by a plant Botanist at the Department of biology and chemistry, Omdurman Islamic university, Khartoum, Sudan.

\subsection{Sample preparation:}

The seeds of Zizyphus spina-christi $L$ were separated manually from the fruits pulp then washed, cleaned, and dried under shade at room temperature, crushed into a fine powder by using in mortar and pestle, packaged in poly ethylene bags for further use.

\subsection{Extraction of oil from Ziziphus spina-christi:}

70 grams of milled seeds of Zizyphus spina-christi L was extracted with organic solvent $n-$ Hexane $\left(40-60^{\circ}\right)$ using a soxhlet extractor for 5 hours. The oil extract that obtained was concentrated under pressure and analysis by GC-MS technique and evaluated for antibacterial and antifungal activities.

\subsection{GC-MS analysis:}

The sample of oil extracted was subjected to GC-MS analysis (GC.MS-QP2010 Ultra, Shimadzu). Injector temperature was $300^{\circ} \mathrm{C}$, and column description: Rtx 5MS -Length 30 meter -Diameter $0.25 \mathrm{~mm}$ - thickness $0.25 \mathrm{ml}$, Temperature programming was maintained from $60^{\circ} \mathrm{C}$ to $300^{\circ} \mathrm{C}$, pressure $100 \mathrm{kpa}$, Total flow $50 \mathrm{ml} / \mathrm{min}$, Column Flow $1.61 \mathrm{ml} / \mathrm{min}$, Linear Velocity $46.3 \mathrm{~cm} / \mathrm{sec}$. The ion source and MS transfer line temperatures were $200^{\circ} \mathrm{C}$, Interface Temp. $250{ }^{\circ} \mathrm{c}$, Solvent Cute Time $2.50 \mathrm{~min}$., the seeds oil were injected with a split less mode. The final confirmation of constituents was compared by computer matching of the mass spectra of peaks with the Wiley and National Institute Standard and Technology (NIST) libraries mass spectral database.

\subsection{Antimicrobial assay:}

The seeds oil of Zizyphus spina-christi L was screened for its antimicrobial activity against five standard human pathogens (Bacilus subtilis (B.S), Staphylococcus aureus (Sa), Escherichia colli $(\mathrm{Ec})$, Pseudomonas aeruginosa $(\mathrm{Pa})$, and Candida albacans $(\mathrm{Ca})$.

\subsubsection{Preparation of bacterial suspensions:}

One $\mathrm{ml}$ aliquots of 24 hours broth culture of the test organisms were aseptically distributed on to nutrient agar slopes and incubated at $37^{\circ} \mathrm{C}$ for 24 hours. The bacterial growth was harvested and washed off with sterile normal saline, and finally suspended in $100 \mathrm{ml}$ of normal saline to produce a suspension containing about 108-109colony forming units per $\mathrm{ml}$. The suspension was stored in the refrigerator at $4^{\circ} \mathrm{C}$ until used. The average number of viable organism per $\mathrm{ml}$ of the stock suspension was determined by means of the surface viable counting technique. Serial dilutions of the stock suspension were made in sterile normal saline in tubes and one drop volumes $(0.02 \mathrm{ml})$ of the appropriate dilutions were transferred by adjustable volume micropipette onto the surface of dry nutrient agar plates. The plates were allowed to stand for two hours at room temperature for the drop to dry, and then incubated at $37^{\circ} \mathrm{C}$ for 24 hours.

\subsubsection{Preparation of fungal suspensions:}

Fungal cultures were maintained on dextrose agar incubated at $25^{\circ} \mathrm{C}$ for four days. The fungal growth was harvested and washed with sterile normal saline, and the suspension was stored in the refrigerator until used.

\subsubsection{Testing for antibacterial activity:}

The cup-plate agar diffusion method was adopted, with some minor modifications, to assess the antibacterial activity. ( $2 \mathrm{ml})$ of the standardized bacterial stock suspension were mixed with $200 \mathrm{ml}$ of sterile molten nutrient agar which was maintained at $45^{\circ} \mathrm{C}$ in a water bath. $(20 \mathrm{ml})$ Aliquots of the incubated nutrient agar were distributed into sterile Petri dishes. The agar was left to settle and in each of these plates which were divided into two halves, two cups in each half (10 $\mathrm{mm}$ in diameter) were cut using sterile cork borer (No 4), each one of the halves was designed for one of the test solutions. Separate Petri dishes were designed for standard antibacterial chemotherapeutics (ampicillin and gentamycin). The agar discs were removed, alternate cups were filled with $0.1 \mathrm{ml}$ samples of each test solution using adjustable volume micro titer pipette and allowed to diffuse at room temperature for two hours. The plates were then incubated in the upright position at $37^{\circ} \mathrm{C}$ for 24 hours. The above procedure was repeated for different concentrations of the test solutions and the standard chemotherapeutics. After incubation, the diameters of the resultant growth inhibition zones were measured in triplicates and averaged.

\section{RESULT AND DISCUSSION:}

\subsection{The GC/MS Analysis of Zizyphus spina-christi Seeds Oil:} The GC-MS spectrum of the Zizyphus spina-christi L seeds oil revealed the presence of 17 components (Table 1).The typical total ion chromatograms (TIC) is depicted in Fig.(3). GC/MS analysis of Zizyphus spina-christi L oil appeared a higher amount of unsaturated fatty acids (61.60\%) than saturated fatty acids $(38.40 \%)$, then unsaturated fatty acids contains monounsaturated fatty acids (46.18\%) and polyunsaturated fatty acids $(15.42 \%)$. The most prominent fatty acids in Zizyphus spina-christi L seeds oil were 9-Octadecenoic acid (38.22\%), 9,12-Octadecadienoic acid $(15.14 \%)$, Hexadecanoic acid (15.10\%), stearic acid (11.14), Cis-13-Eicosenoic acid (7.15\%), Eicosanoic acid (6.24) and Docosanoic acid (4.60), other fatty acids which a counted in percentage of the total fatty acids is small amount. 
Table (1): Fatty acids constituent of Zizyphus spina-christi seeds oil

\begin{tabular}{|c|c|c|c|}
\hline $\begin{array}{l}\text { Peak } \\
\text { No. }\end{array}$ & Name & R.Time & Area $\%$ \\
\hline 1 & Methyl tetradecanoate & 14.191 & 0.26 \\
\hline 2 & Pentadecanoic acid ,methyl ester & 15.325 & 0.06 \\
\hline 3 & $\begin{array}{lll}\text { 7-Hexadecenoic acid, methyl } \\
\text { ester,(Z) }\end{array}$ & 16.163 & 0.15 \\
\hline 4 & $\begin{array}{l}\text { 9-Hexadecenoic acid, methyl ester, } \\
\text { (Z). }\end{array}$ & 16.21 & 0.25 \\
\hline 5 & Hexadecanoic acid, methyl ester & 16.445 & 15.1 \\
\hline 6 & $\begin{array}{l}\text { Cis-10- heptadecenoic acid, methyl } \\
\text { ester }\end{array}$ & 17.227 & 0.16 \\
\hline 7 & Heptadecanoic acid, methyl ester & 17.442 & 0.34 \\
\hline 8 & $\begin{array}{l}\text { 9,12-Octadecadienoic } \\
\text { (Z,Z),methyl ester }\end{array}$ & 18.225 & 15.14 \\
\hline 9 & $\begin{array}{l}\text { 9-Octadecenoic acid (Z),methyl } \\
\text { ester }\end{array}$ & 18.333 & 38.22 \\
\hline 10 & Methyl Stearate & 18.475 & 11.14 \\
\hline 11 & Trans-Geranylgeraniol & 19.152 & 0.28 \\
\hline 12 & $\begin{array}{l}\text { Cis-13-Eicosenoic acid, methyl } \\
\text { ester }\end{array}$ & 20.087 & 7.15 \\
\hline 13 & Eicosanoic acid, methyl ester & 20.288 & 6.24 \\
\hline 14 & Heneicosanoic acid, methyl ester & 21.145 & 0.26 \\
\hline 15 & 13-Docosanoic acid, methyl ester & 21.8 & 0.25 \\
\hline 16 & Docosenoic acid, methyl ester & 21.986 & 4.6 \\
\hline 17 & Tricosanoic acid, methyl ester & 22.781 & 0.4 \\
\hline \multicolumn{3}{|c|}{ Total } & $100 \%$ \\
\hline \multicolumn{3}{|c|}{ Saturated fatty acids } & 38.4 \\
\hline \multicolumn{3}{|c|}{ 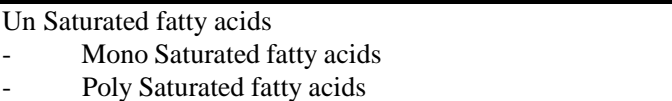 } & $\begin{array}{l}61.60 \\
46.18 \\
15.42\end{array}$ \\
\hline
\end{tabular}

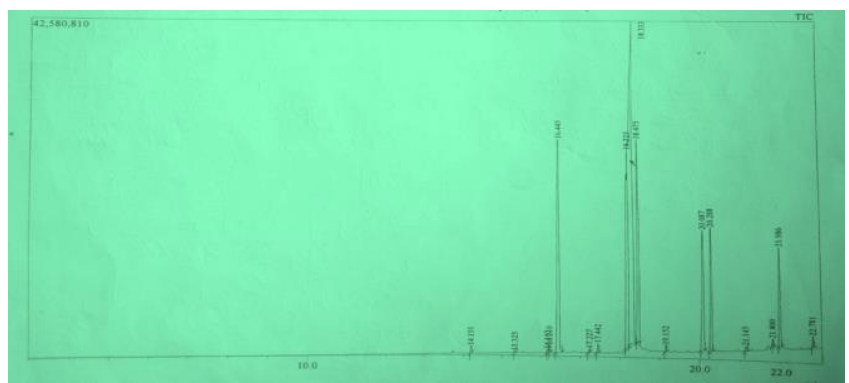

Fig. (3): Zizyphus spina-christi L seeds oil Chromatogram

\subsection{Antimicrobial Screening:}

The oil of Zizyphus spina-christi L seeds is effective against most of the microorganism assayed. Shown in Table (2) the average of the diameters of the growth inhibition zones. The Zizyphus spina-christi L seeds oil tasted of microorganism showed high activity against Staphylococcus auras (S.a) but it is un active against Pseudomonas aeruginosa (Pa) and Bacillus subtilis (B.S), Escherichia coli (E.s). And also a good activity against fungi Candida.

Table (2): Antimicrobial activity of standard drugs and Z. spina-christi L seed oil

\begin{tabular}{|l|c|c|c|c|c|}
\hline \multirow{2}{*}{$\begin{array}{l}\text { Name } \\
\text { compound }\end{array}$} & \multicolumn{4}{|c|}{ Minimal inhibition concentration $(\mu \mathrm{g}$ mL-1 ) } \\
\cline { 2 - 6 } & \multicolumn{2}{|c|}{ Gram-negative } & \multicolumn{2}{|c|}{ Gram-positive } & $\begin{array}{c}\text { Fungal } \\
\text { species }\end{array}$ \\
\cline { 2 - 6 } & P.a & E.c. & B.s. & S.a & C.a \\
\hline Ciprofloxacin & 25 & 25 & 50 & 50 & - \\
\hline Greseofulvin & - & - & - & - & 500 \\
\hline $\begin{array}{l}\text { Zizyphus } \\
\text { spina-christi L oil }\end{array}$ & - & - & - & 15 & 18 \\
\hline
\end{tabular}

\section{CONCLUSIONS}

Zizyphus spina-christi L has been traditionally used in the cure of various diseases, as we have illustrated in this study. The various parts of the plant have been explored for ant diabetic, antimicrobial and anti-inflammatory, an antispasmodic, insecticidal, and many other pharmacological and medicinal uses. The fatty acids identification in this study it may be give a new biologically activity.

\section{ACKNOWLEDGMENTS}

The authors would like to thank all members of Department of Chemistry and Biology and the member of laboratory of chemistry and ustaz Abdel salam.

\section{REFERENCES}

[1]Fatima A., Nuha,M.,(2018): Chemotaxonomic study and botanical overview of some Ziziphus spp. In sudan; Int. Res. J. Biological Sci. Vol. 7(5), 32-39.

[2] Amina S., Jens G., Karl H., Andreas B.,(2008); Ziziphus spina-christi (L.) Willd.: a multipurpose fruit tree, Genet Resour Crop, Evol , 55:929-937.

[3]A. M. Bukar, M. Z. Kyari, P. A. Gwaski, M. Gudusu, F. S. Kuburi and Y. I. Abadam,(2015); Evaluation of phytochemical and potential antibacterial activity of Ziziphus spina-christi L. against some medically important pathogenic bacteria obtained from University of Maiduguri Teaching Hospital, Maiduguri, Borno State - Nigeria, Journal of Pharmacognosy and Phytochemistry , 3(5): 98-101.

[4] Kaiser N., Rana A., Firas M., Zaineb H.,(2015); The Effects of Zizyphus Stem Bark and Termite Shelter Tubes on HeLa cell Growth, Res. J. of Pharm., Bio. and Chem. Sci.,6(6),22.

[5]Zeinelabdin M.,(2016); Variation of some morphological characteristics of Ziziphs spina-chriti (A.) Ritch. fruits among four provenances, Inter. J. of Sci. and Res., Vol. 6(5),433.

[6] Vandita S.,Nejib G.,Musthafa M.,Mohamed S.,Subash S.,(2012); In vitro Antioxidant of Ziziphus spina-chrisiti Fruits (Red Date) Grown in Oman, Biotechnology,11(5),209-216.

[7] Essam N., Saravanan R., Syed I., Sherif M., Jamal R.,(2018); Phytochemical screening of different organic crude extracts from the stem bark of Ziziphus spina-christi (L.). Biomedical Research; 29 (8), 1645-1652.

[8]El-Kamali HH, El-Khalifa KF (1999) Folk medicinal plants of riverside forests of the Southern Blue Nile district, Sudan. Fitoterapia 70:493-497.

[9]Mohamed G., Laura Q., Ahmed R., Rakesh J., Maren R., Matthias S., Klaudia B.,Nikolai K.,(2016); Phenolic Profile and In Vitro Assessment of Cytotoxicity and Antibacterial Activity of Ziziphus spina-christi leaf Exterct, Med chem (Los Angeles),Volume 6(3): 143-156.

[10] M. E. Abalaka1*, S. Y. Daniyan1 and A. Mann,(2010); Evaluation of the antimicrobial activities of two Ziziphus species (Ziziphus mauritiana L. and Ziziphus spinachristi L.) on some microbial pathogens. African J. of Pharmacy and Pharmacology Vol. 4(4), pp. 135-139,

[11] Ali-Shtayeh MS, Yaghmour MR, Faidi YR, Salem K, Al-Nuri MA (1998) Antimicrobial activity of 20 plants used in folkloric medicine in the Palestinian area. J Ethnopharmacol 60:265-271

[12] Hossein M., Seyyed M., Zahra H., Fariba D.,(2014); A Comparative Study on the Effects of Ziziphus Spina-christi Alcoholic Extracts on Growth and Structural Integrity of Bacterial Pathogens, Iranian J. of Pharmaceutical Sci. 10 (2): 1 - 10.

[13] Ghafoor AO, Qadir HK, Fakhri NA.,(2012); Analysis of phenolic compounds in extracts of Ziziphus spina-christi using RPHPLC methods. J Chem Pharm Res., 4: 3158-3163.

[14] Abd El-Hameed A.,(2017); Using Natural Polyphenol Extracts of Sider (Zizyphus spina-christi L.) Leaves and Seeds as Anti-Microbial, Middle East J. Appl. Sci., Vol. 7 (2) :262-271 